\title{
Serum lipids and lipoproteins in malaria - a systematic review and meta-analysis
}

Benjamin J Visser ${ }^{1,2,4}$, Rosanne W Wieten ${ }^{1,2}$, Ingeborg M Nagel ${ }^{3}$ and Martin P Grobusch 1,2,4*

\begin{abstract}
Background: Serum lipid profile changes have been observed during malaria infection. The underlying biological mechanisms remain unclear. The aim of this paper is to provide an overview on those serum lipid profile changes, and to discuss possible underlying biological mechanisms and the role of lipids in malaria pathogenesis.

Methods: A systematic review and meta-analysis to determine lipid profile changes during malaria was conducted, following PRISMA guidelines. Without language restrictions, Medline/PubMed, Embase, Cochrane Central Register of Controlled Trials, Web of Science, LILACS, Biosis Previews and the African Index Medicus were searched for studies published up to 11 July, 2013, that measured serum lipid parameters in malaria patients. Also, major trial registries were searched. Mean differences in lipid profile parameters were combined in fixed and random effects meta-analysis, with a separate analysis for different groups of controls (healthy, other febrile illnesses or very low parasitaemia). These parameters were also compared between severe malaria and uncomplicated malaria. Funnel plots were used to test for publication bias.
\end{abstract}

Results: Of 2,518 studies reviewed, 42 met the criteria for inclusion in the qualitative analysis, and of these, 15 reported the necessary data for inclusion in the meta-analysis for cholesterol; nine for high-density lipoprotein (HDL), eight for low-density lipoprotein (LDL), and nine for triglycerides, respectively. Total cholesterol, HDL and LDL concentrations were lower in malaria and other febrile diseases compared to healthy controls. The decline was more pronounced and statistically significant during malaria compared to other febrile diseases. These results were consistent across included studies. Triglycerides were raised compared to healthy controls, but not statistically significant when compared to symptomatic controls.

Conclusions: This meta-analysis suggests that the observed lipid profile changes are characteristic for malaria. Although a definite link with the pathogenesis of malaria cannot yet be demonstrated, plausible hypotheses of biological mechanisms involving host lipid alterations and the pathogenesis of malaria exist. An increased research effort to elucidate the precise pathways is warranted, since this could lead to better understanding of malaria pathophysiology and consequently to novel treatment approaches.

Keywords: Malaria, Lipids, Meta-analysis, Cholesterol, Lipoproteins, High-density lipoprotein (HDL), Low-density lipoprotein (LDL), Very low-density lipoprotein (VLDL), Triglycerides, Haemozoin (Hz)

\footnotetext{
* Correspondence: m.p.grobusch@amc.uva.nl

'Centre of Tropical Medicine and Travel Medicine, Department of Infectious

Diseases, Academic Medical Centre, University of Amsterdam, Meibergdreef

9, PO Box 226601100 DD, Amsterdam, The Netherlands

Full list of author information is available at the end of the article
}

\section{Biomed Central}

(c) 2013 Visser et al.; licensee BioMed Central Ltd. This is an Open Access article distributed under the terms of the Creative Commons Attribution License (http://creativecommons.org/licenses/by/2.0), which permits unrestricted use, distribution, and reproduction in any medium, provided the original work is properly cited. The Creative Commons Public Domain Dedication waiver (http://creativecommons.org/publicdomain/zero/1.0/) applies to the data made available in this article, unless otherwise stated. 


\section{Background}

Patients with malaria often exhibit laboratory abnormalities due to an acute phase response, but little is known about serum lipid profile changes in malaria. In 1978, Lambrecht et al. [1] reported transient lipid profile changes in six returning travellers with malaria caused by Plasmodium vivax and suggested for the first time that changes in high-density lipoprotein (HDL) and very low-density lipoprotein (VLDL) in human serum are related to the lipid metabolism of the parasite. It was hypothesized that the malaria parasite uses cholesterol and phospholipids from its host, resulting in a decrease of serum HDL. Prior to this report, Angus et al. [2-4] utilized lipoprotein electrophoresis in rhesus monkeys infected with Plasmodium knowlesi to study serum lipids in malaria. Their results were not conclusive because lipoprotein bands could barely be detected in the serum of controls. Subsequently, several clinical studies showed lipid profile changes in the setting of both uncomplicated and complicated malaria [5-10]. Although the magnitude of changes seems to be related to the severity of malaria in several studies [11,12], others found no correlation between the severity of malaria attacks and the extent of lipid profile changes [13,14]. These transient lipid profile changes in the parasitaemic phase have been suggested by some researchers as a potential adjuvant diagnostic tool for malaria $[13,15,16]$.

Changes in serum lipid profile and lipid metabolism are due to a whole range of at least partially disease-specific mechanisms [17]. The extent of serum lipid profile changes during malaria infection and their underlying biological mechanisms remain unclear. Mechanisms may be partly host related (i e, related to an acute phase reaction [18]), parasite-related [19-21], or a combination of these two. If a link between human host serum lipid alterations and the pathogenesis of malaria can be demonstrated, further studies to elucidate the precise pathways can be conducted. Moreover, novel treatment approaches could be explored with lipid metabolism-regulating drugs. Therefore, it is hypothesized that the lipid profile of malaria exhibits characteristic changes. In addition, it is understood that these changes are specific for the malaria pathogenhost interplay.

\section{Objectives}

The present systematic review aims at identifying serum lipid profile changes in malaria with respect to commonly used laboratory parameters: (total) cholesterol (TC), high-density lipoprotein cholesterol (HDL), lowdensity lipoprotein cholesterol (LDL), very low-density lipoprotein cholesterol (VLDL) and triglycerides (TG). Also, intermediate density lipoproteins (IDL) and apolipoproteins (all classes) are investigated. Furthermore, different possible underlying biological mechanisms and the role of lipids in the pathogenesis of malaria are discussed.

\section{Methods}

Methods of the present review, objectives and inclusion criteria were specified in advance and documented in a protocol (see Additional file 1) [22]. Recommendations made by the Meta-analysis of Observational Studies in Epidemiology (MOOSE) and the Preferred Reporting Items for Systematic Reviews and Meta-Analyses (PRISMA) groups [23-25] were followed. The electronic databases Medline/PubMed (1946 to July 2013), Embase (via Ovid, 1947 to July 2013), Cochrane Central Register of Controlled Trials (The Cochrane Library, 10 July 2013), Web of Science (1975 to July 2013), LILACS (Latin-American and Caribbean Health Sciences Literature; 1982 to July 2013), Biosis Previews (1993 to July 2013) and the African Index Medicus (1993 to July 2013) were searched in order to identify studies published up to present. In addition, major trial registries [26,27] were searched to identify ongoing or future trials. The search strategy consisted of free-text words and subject headings related to malaria and serum lipids. The search strategy was not limited by study design or language. The full search strategies for every searched database are reported in Additional file 2. An experienced clinical librarian (IMN) conducted the actual searches on 9, 10 and 11 July 2013. Bibliographies of relevant studies retrieved from the studies were checked for additional publications. Reference Manager 12.0.3 (Thomson Reuters) was used to manage, de-duplicate and screen the references for eligibility. Reports published before a certain point in time were not excluded. Selection criteria for inclusion of retrieved studies were as follows; the study population consisted of patients with malaria (Plasmodium falciparum, Plasmodium ovale, $P$. vivax, Plasmodium malariae and $P$. knowlesi) of all age groups. Also, at least one of the following outcomes of interest was measured: a) TC; b) HDL; c) LDL; d) IDL; e) VLDL; f) apolipoproteins (all classes); g) TG. All types of studies, including cross-sectional, casecontrol, case-report and cohort studies were included in the qualitative analysis. To prevent bias, studies with and without (healthy) controls were included. Animal studies were excluded because it is doubtful whether animal studies are comparable to humans regarding lipid profile changes during malaria. Eligibility assessment of studies was performed independently in an unblinded, standardized way by two reviewers (BJV and RWW). Titles and abstracts were screened first, and then one reviewer (BJV) screened and selected relevant full-text articles. For quality control, RWW reviewed 60 (50\%) randomly selected full-text articles screened. One author (BJV) extracted the following study characteristics: first author, year of publication, language, study setting, study design, characteristics of trial participants, type and number of controls, type of outcome 
lipid parameter (TC, HDL, IDL, LDL, VLDL, TG and apolipoproteins) and, if provided, sensitivity/specificity and positive- and negative predictive values. The time of measurement of the outcomes of interest was at admission ("Day 0") and before anti-malarial treatment. Data was double checked by RWW for all articles included $(n=42)$. Disagreements in the selection process between reviewers were resolved by consensus or on consultation with the senior author (MPG). The study selection process is summarized in the PRISMA flow diagram (see Figure 1). Authors were not contacted for further information, or to confirm the accuracy of information included in our review with the original researchers, since for the majority of papers adequate contact information was missing. Risk-of-bias assessments for studies included in the quantitative synthesis were made (see Additional file 3). No studies were excluded on the basis of quality.

The existence of publication bias was investigated using funnel plots [28]. A funnel plot is a scatter plot of (treatment) effect against a measure of study size. The risk of publication bias is most probably larger for observational studies than randomized controlled trials, particularly small observational studies as included in this present review [29]. For this reason, the overall publication bias risk for this systematic review is considered as substantial.

\section{Statistical analysis}

Studies that met the eligibility criteria and that reported means and standard deviation (SD), or presented sufficient data for the calculation of means and/or SD, were included in the meta-analysis. The inverse-variance method for the meta-analysis, in which weight is given to each study according to the inverse of the variance of the effect, in order to minimize uncertainty about the pooled effect estimates (see Additional file 4: Statistical analysis). The studies included were allocated into four groups: cholesterol, HDL, LDL, and triglycerides. Studies with healthy controls and symptomatic controls were analysed separately. If studies presented results for uncomplicated as well as for severe malaria [12,30,31], the combined data were used (see Additional file 4). Stratified analyses for

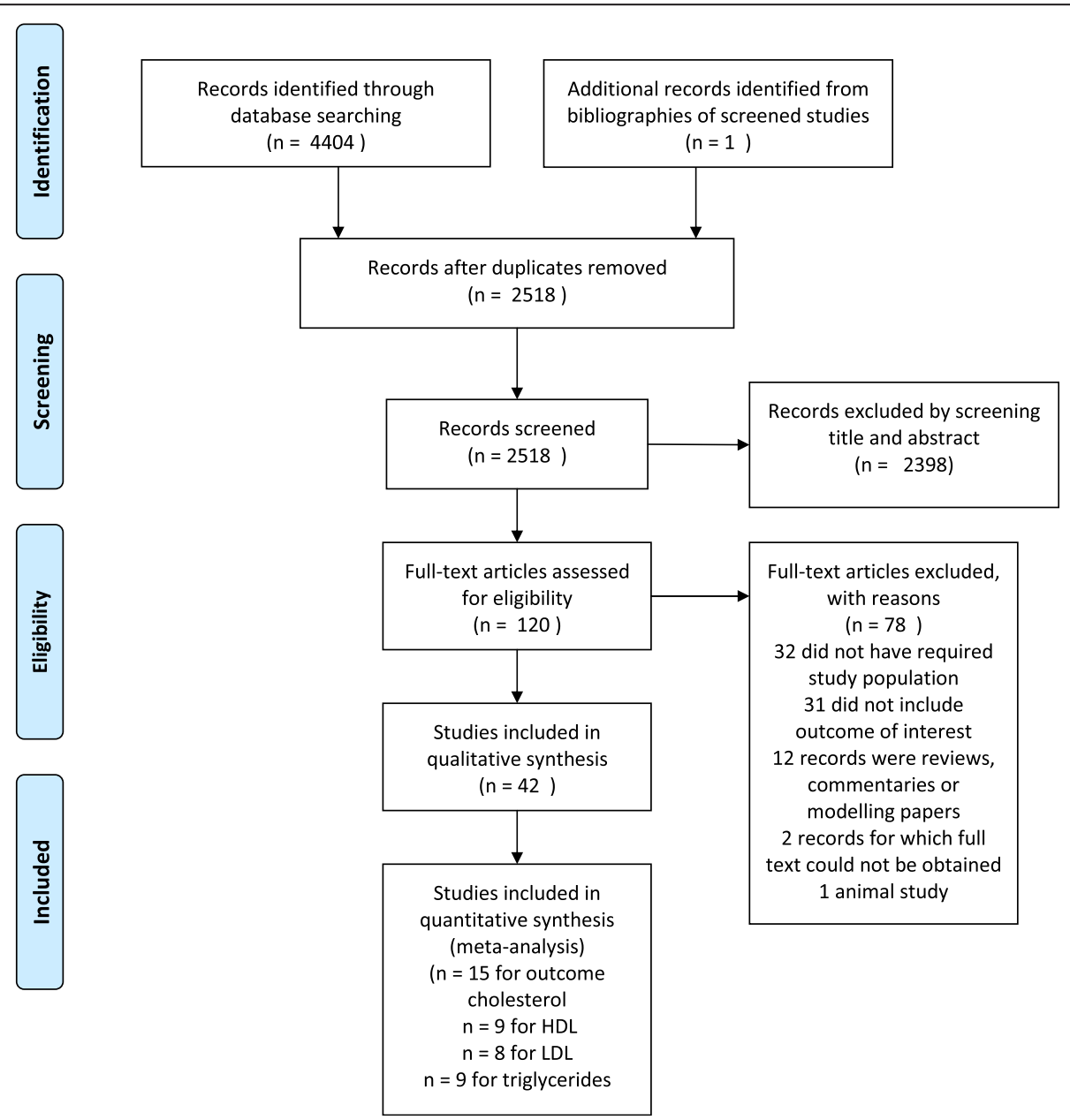

Figure 1 Study selection (PRISMA flow diagram). 
uncomplicated and severe malaria were conducted (see Additional file 5). Data were entered by RWW and checked by BJV. Missing data were not problematic since meta-regression of individual data was not done. The $\mathrm{I}^{2}$ and $95 \% \mathrm{CI}$ were used to quantify heterogeneity. $\mathrm{I}^{2}$ represents the percentage of the total variation in estimated effects across studies, which is due to real heterogeneity rather than to chance [23]. Initially a fixed effect metaanalysis was performed; however, if $\mathrm{I}^{2}$ was large $(>50 \%)$, which suggests substantial heterogeneity, random-effects analysis was used. Forest and funnel plots were produced to visually assess the mean difference(s) and SD of each study (see Additional file 6). Analyses were done with RevMan 5.2 (Review Manager 5.26. Copenhagen: The Nordic Cochrane Centre, The Cochrane Collaboration, 2012).

\section{Results}

The initial search yielded 4,406 records of which 2,518 remained after removal of duplicates (see Figure 1). Fortytwo records [1,5-16,30-57] met the inclusion criteria (Additional file 7: Table S1). Of these, $\mathrm{n}=15$ for cholesterol $[7,9,10,12,30,31,33,35,38,40,42,44,46,50,52,54]$; nine for HDL [10,12,30,33,35,38,42,44,52]; eight for LDL [10,12, $30,33,35,38,42,52]$; nine for triglycerides [10,12,30,33,35, $40,42,50,52]$, contained the necessary data for inclusion in the quantitative analysis (meta-analysis); see PRISMA flow diagram (Figure 1). Four records $[11,13,14,47]$ were excluded from the quantitative synthesis either because means and SD were not reported $(\mathrm{n}=3)$, or mean differences and SD could not be calculated from the available data $(n=1)$. For one record, a case report [57], the full text was not retrievable. The meta-analysis was done for cholesterol, HDL, LDL and triglycerides (see Additional file 6). For other parameters, such as the apolipoproteins, IDL and VLDL, there was insufficient data to perform a quantitative analysis. If only one study was to be included in the meta-analysis, the forest plot is not shown. For each outcome, two comparisons were made. The first comparison compared means of malaria cases with healthy controls. The second comparison compared malaria cases with symptomatic controls (malaria-like symptoms, but negative for malaria). This second comparison is important as it can indicate whether alterations in lipid profile parameters are malaria specific or also occur in other febrile diseases.

\section{Description of included studies}

For all articles except one [57], the full text paper could be retrieved. The majority of records was published in English; however, 31\% (13/42) were in another language (of which French - 19\%, 8/42; others 12\%, 5/42). Eightythree percent $(35 / 42)$ of the records were found using only Medline/PubMed. Fourteen studies took place in sub-Saharan Africa; ten in (Southeast) Asia; 16 in
Western countries (Europe, USA, Australia); and two in South America. In total, 3,442 patients with malaria were analysed in these studies, and compared with 1,686 controls (patients negative for malaria). Thirty-five were adult studies and seven were paediatric studies $[14,30,31$, $36,44,52,55]$. In 26 of these 42 records, serum lipid profiles of malaria patients were compared to a control group. These control groups consisted of healthy controls (15 studies) $[7,9,11,12,14,30,31,33,38,40,44,47,50]$ or "symptomatic" controls $[16,35,37,44,46]$ (malaria-like symptoms but negative for malaria). There were two records including controls with a (very) low parasitaemia [10,32]; one of these two [32] did not report the necessary data and was therefore excluded from the meta-analysis; the other study [10] was included in the meta-analysis for healthy controls. A separate analysis was also performed without this study [10]; these results are reported in Additional file 8. In four studies, both healthy controls and symptomatic controls were recruited $[13,35,44,46]$ and compared. In two studies, the controls were not adequately described [41,42]. These two studies were considered as studies with healthy controls. Reference values and measurement units varied considerably among the included studies and were often not reported.

\section{Cholesterol}

Serum total cholesterol was measured in 36 of 42 included studies. 83\% (30/36 studies) reported a hypocholesterolaemia in patients with malaria or a significantly lowered total cholesterol level compared to the control group. Two studies reported a raised cholesterol $[36,41]$, three studies showed no significant differences with the control group $[9,39,43]$ and one study was inconclusive [48] (see Additional file 7: Table S1 for details). Forest plot 1 ( $\mathrm{n}=$ 15) (Figure 2) shows the mean difference for cholesterol in malaria patients versus healthy controls: $1.09 \mathrm{mmol} / \mathrm{l}$ or $42.15 \mathrm{mg} / \mathrm{dl}(95 \%$ CI $0.74-1.44 \mathrm{mmol} / \mathrm{l}), \mathrm{I}^{2}=98 \%, \mathrm{Z}=6.14$ $\mathrm{P}<0.00001$. Forest plot $2(\mathrm{n}=3)$ (Figure 3$)$ shows the mean difference for cholesterol in malaria patients versus symptomatic controls: $0.79 \mathrm{mmol} / \mathrm{l}$ or $30.55 \mathrm{mg} / \mathrm{dl}(95 \%$ CI $0.13-1.45 \mathrm{mmol} / \mathrm{l}), \mathrm{I}^{2}=90 \%, \mathrm{Z}=2.34, \mathrm{P}=0.02$. Thus, cholesterol is significantly decreased during malaria. For severe malaria, a separate analysis including three studies $[12,30,31]$ was performed (Additional file 5). Mean difference for cholesterol in severe malaria patients versus healthy controls was $1.60 \mathrm{mmol} / \mathrm{l}$ or $61.87 \mathrm{mg} / \mathrm{dl}(95 \% \mathrm{CI}$ $0.66-2.54), \mathrm{I}^{2}=99 \%, \mathrm{Z}=3.33, \mathrm{P}=0.0009$.

\section{High-density lipoprotein (HDL)}

In 23 of 42 studies HDL was measured during malaria. Eighty-seven percent (20/23 studies) reported a large decline in HDL-concentrations. Forest plot $3(n=9)$ (Figure 4) shows the mean difference for HDL in malaria patients versus healthy controls: $0.32 \mathrm{mmol} / \mathrm{l}$ or $12.37 \mathrm{mg} / \mathrm{dl}$ 


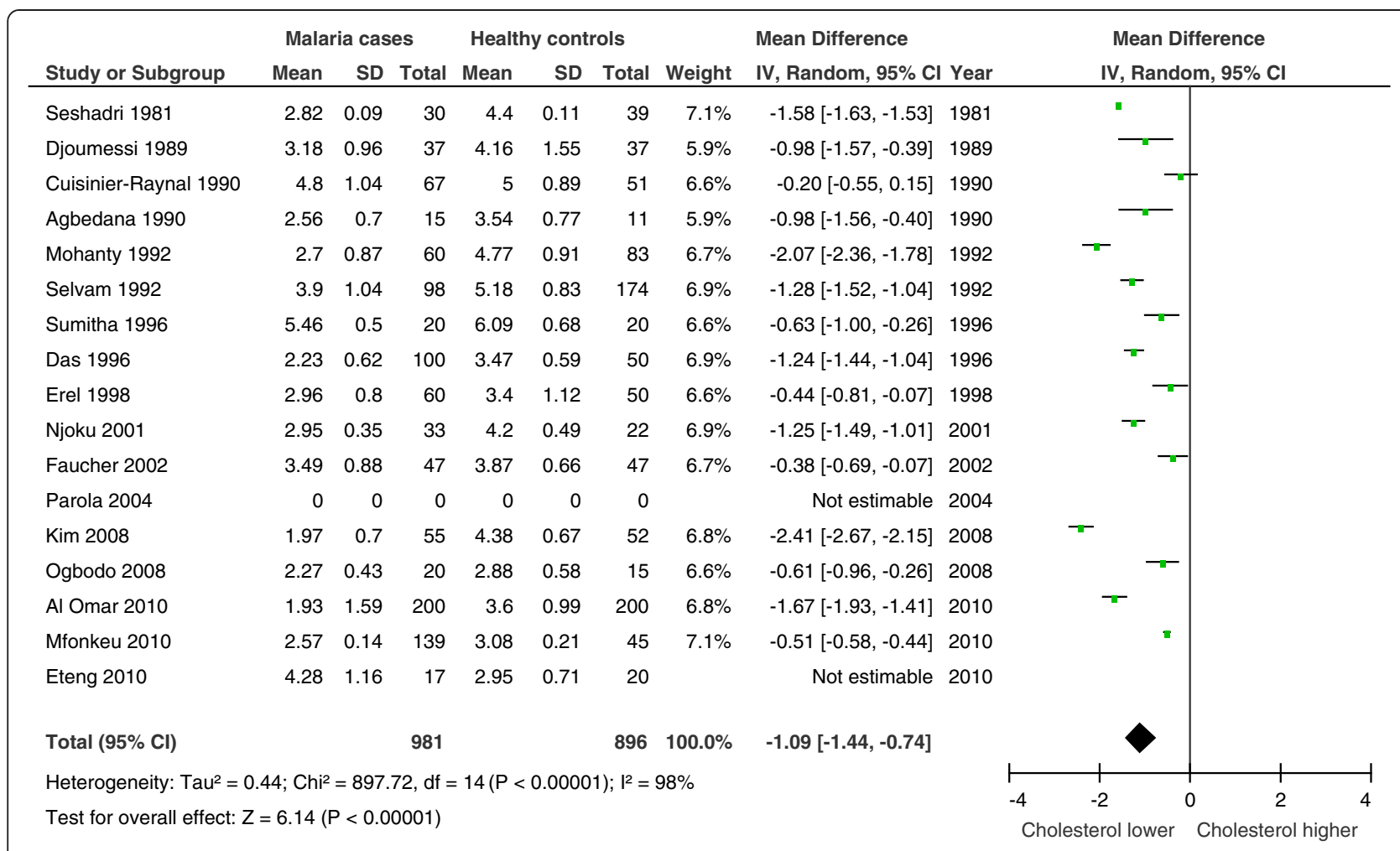

Figure 2 Forest plot Mean difference for cholesterol ( $\mathrm{mmol} / \mathrm{l})$ between malaria patients and healthy controls. Random-effect model.

(95\% CI 0.02-0.63 mmol/l), $\mathrm{I}^{2}=99 \%, \mathrm{Z}=2.08, \mathrm{P}=0.04$. Forest plot $4(\mathrm{n}=2)$ (Figure 5$)$ shows the mean difference for HDL in malaria patients versus symptomatic controls: $0.39 \mathrm{mmol} / \mathrm{l}$ or $15.08 \mathrm{mg} / \mathrm{dl}$ (95\% CI $0.07-0.72 \mathrm{mmol} / \mathrm{l}$ ), $\mathrm{I}^{2}=85 \%, \mathrm{Z}=2.39, \mathrm{P}=0.02$. Two studies $[30,31]$ showed a significant larger decline in HDL in severe malaria compared to uncomplicated malaria. Thus, HDL is significantly lower in malaria.

\section{Low-density lipoprotein (LDL)}

In 16 of 42 studies LDL was measured during malaria. Eighty-one percent (13/16 studies) reported a lower LDL-c concentration in malaria patients. Forest plot 5 $(\mathrm{n}=8)$ (Figure 6) shows the mean difference for LDL in malaria patients versus healthy controls: $0.82 \mathrm{mmol} / \mathrm{l}$ or $31.71 \mathrm{mg} / \mathrm{dl}(95 \%$ CI $0.24-1.39 \mathrm{mmol} / \mathrm{l}), \mathrm{I}^{2}=97 \%, \mathrm{Z}=$ $2.79, \mathrm{P}=0.005$. Only one study compared LDL in malaria patients with symptomatic controls and found a difference of $1.67 \mathrm{mmol} / \mathrm{l}$ or $64.58 \mathrm{mg} / \mathrm{dl}$ (95\% CI 1.44$1.90 \mathrm{mmol} / \mathrm{l}), \mathrm{P}<0.01[35]$. Two studies [30,31] showed a significant larger decline in LDL in patients with severe malaria compared to patients with uncomplicated malaria. Thus, LDL is significantly lower in malaria.

\section{Triglycerides}

In 23 of 42 studies triglycerides were measured during malaria. Seventy-eight percent (18/23 studies) reported a hypertriglyceridemia and/or a significantly higher mean triglyceride plasma concentration in malaria patients compared to controls. Forest plot $6(n=9)$ (Figure 7 ) shows the mean difference for triglycerides in malaria patients versus healthy controls: $0.25 \mathrm{mmol} / \mathrm{l}$ or $22.14 \mathrm{mg} / \mathrm{dl}$ (95\% CI 0.12-0.37 mmol/l), $\mathrm{I}^{2}=82 \%, \mathrm{Z}=3.79, \mathrm{P}=0.0002$. Forest plot $7(\mathrm{n}=2)$ (Figure 8$)$ shows the mean difference for triglycerides in malaria patients versus symptomatic controls: $0.42 \mathrm{mmol} / \mathrm{l}$ or $37.20 \mathrm{mg} / \mathrm{dl}$ (95\% CI 0.46 $1.31 \mathrm{mmol} / \mathrm{l}), \mathrm{I}^{2}=95 \%, \mathrm{Z}=0.94, \mathrm{P}=0.35$. Thus, triglycerides are significantly higher in malaria patients compared to healthy controls, but these differences become nonsignificant when compared to symptomatic controls. In patients with severe malaria triglyceride levels were found to be higher compared to triglyceride levels in patients with uncomplicated malaria [12,30].

\section{Very low-density lipoprotein (VLDL)}

Five studies measured VLDL during malaria, of which one case report found marked bands of VLDL [6]. No meta-analysis could be conducted due to insufficient data. In a consecutive case-series in six patients with $P$. vivax malaria, three of six patients had VLDL levels below detection limits [1]. A small cross-sectional study in returning travellers with malaria $(n=12)$ found a raised plasma VLDL-c in nine of ten patients [8]. This finding was confirmed in another study with 110 malaria 


\begin{tabular}{|c|c|c|c|c|c|c|c|c|c|c|c|}
\hline \multirow[b]{2}{*}{ Study or Subgroup } & \multicolumn{3}{|c|}{ Malaria cases } & \multicolumn{3}{|c|}{ Symptomatic cases } & \multirow[b]{2}{*}{ Weight } & \multirow{2}{*}{\multicolumn{2}{|c|}{$\begin{array}{l}\text { Mean Difference } \\
\text { IV, Random, } 95 \% \mathrm{CI} \text { Year }\end{array}$}} & \multirow{2}{*}{\multicolumn{2}{|c|}{$\begin{array}{c}\text { Mean Difference } \\
\text { IV, Random, } 95 \% \mathrm{CI}\end{array}$}} \\
\hline & Mean & SD & Total & Mean & SD & Total & & & & & \\
\hline Seshadri 1981 & 0 & 0 & 0 & 0 & 0 & 0 & & Not estimable & 1981 & & \\
\hline Djoumessi 1989 & 0 & 0 & 0 & 0 & 0 & 0 & & Not estimable & 1989 & & \\
\hline Cuisinier-Raynal 1990 & 0 & 0 & 0 & 0 & 0 & 0 & & Not estimable & 1990 & & \\
\hline Agbedana 1990 & 2.56 & 0.7 & 15 & 2.87 & 0.7 & 15 & $30.8 \%$ & $-0.31[-0.81,0.19]$ & 1990 & $一$ & \\
\hline Kittl 1992 & 0 & 0 & 0 & 0 & 0 & 0 & & Not estimable & 1992 & & \\
\hline Mohanty 1992 & 0 & 0 & 0 & 0 & 0 & 0 & & Not estimable & 1992 & & \\
\hline Selvam 1992 & 3.9 & 1.04 & 98 & 4.49 & 0.69 & 28 & $34.3 \%$ & $-0.59[-0.92,-0.26]$ & 1992 & - & \\
\hline Davis 1993 & 0 & 0 & 0 & 0 & 0 & 0 & & Not estimable & 1993 & & \\
\hline Das 1996 & 0 & 0 & 0 & 0 & 0 & 0 & & Not estimable & 1996 & & \\
\hline Sumitha 1996 & 0 & 0 & 0 & 0 & 0 & 0 & & Not estimable & 1996 & & \\
\hline Erel 1998 & 0 & 0 & 0 & 0 & 0 & 0 & & Not estimable & 1998 & & \\
\hline Njoku 2001 & 0 & 0 & 0 & 0 & 0 & 0 & & Not estimable & 2001 & & \\
\hline Faucher 2002 & 0 & 0 & 0 & 0 & 0 & 0 & & Not estimable & 2002 & & \\
\hline Parola 2004 & 0 & 0 & 0 & 0 & 0 & 0 & & Not estimable & 2004 & & \\
\hline Ogbodo 2008 & 0 & 0 & 0 & 0 & 0 & 0 & & Not estimable & 2008 & & \\
\hline Kim 2008 & 1.97 & 0.7 & 55 & 3.37 & 0.68 & 34 & $34.9 \%$ & $-1.40[-1.69,-1.11]$ & 2008 & -1 & \\
\hline Mfonkeu 2010 & 0 & 0 & 0 & 0 & 0 & 0 & & Not estimable & 2010 & & \\
\hline Eteng 2010 & 0 & 0 & 0 & 0 & 0 & 0 & & Not estimable & 2010 & & \\
\hline Al Omar 2010 & 0 & 0 & 0 & 0 & 0 & 0 & & Not estimable & 2010 & & \\
\hline Total $(95 \% \mathrm{Cl})$ & & & 168 & & & 77 & $100.0 \%$ & $-0.79[-1.45,-0.13]$ & & & \\
\hline \multicolumn{10}{|c|}{ Heterogeneity: $\mathrm{Tau}^{2}=0.30 ; \mathrm{Chi}^{2}=19.81, \mathrm{df}=2(\mathrm{P}<0.0001) ; \mathrm{I}^{2}=90 \%$} & $\longmapsto$ & $\begin{array}{ll}1 & \\
2 & 4\end{array}$ \\
\hline \multicolumn{10}{|c|}{ Test for overall effect: $Z=2.34(P=0.02)$} & $\begin{array}{l}-4 \\
\text { Cholesterol lower }\end{array}$ & ${ }^{2}{ }^{2}{ }^{4}$ \\
\hline
\end{tabular}

patients (both $P$. falciparum and $P$. vivax) with a control group ( $\mathrm{n}=$ not reported) which found a raised mean concentration compared to the controls $(p<0.05)$ [41]. An observational study in French soldiers reported "no significant difference found for VLDL" but did not report means and p-values [9].

\section{Intermediate-density lipoprotein (IDL)}

None of the included studies measured or reported intermediate-density lipoprotein (IDL) during malaria.

\section{Apolipoproteins}

Apolipoproteins were measured in five studies. No metaanalysis could be conducted due to insufficient data. A patient with Tangier disease and P. falciparum was reported to have apolipoprotein A1 levels below detection levels [34]. A small cross-sectional study with 37 P. falciparum patients and 37 healthy controls also found a decrease in apoliprotein $\mathrm{A}$ in patients compared to controls, but a higher concentration of apolipoprotein B in malaria patients [38]. Kittl et al. [13] observed apolipoprotein A and A-1 lowered in malaria patients, and a very strong correlation with HDL-c ( $r=0.96$ for Apo A and $r=0.95$ for Apo A-1). However, mean values for the malaria group and the control group are not reported. No significant differences between patients and controls for apolipoprotein A1, A2 or B were found by Cuisinier-Raynal [9]; however, mean or p-values were not reported. A pilot descriptive prospective cross-sectional study to investigate the link between nutrition and immunity in Colombian children showed significantly lowered apolipoprotein A1 levels in the malaria group compared to the healthy controls [55].

\section{Duration of lipid profile changes}

The time for malaria patients to recover from the serum lipid profile alterations varied widely across studies. Eight studies [8,10,12,15,34-36,39] reported measurements after "day 0" (admission, before anti-malarial treatment). In most studies, lipid parameters resolved slowly; in one study levels of cholesterol, HDL and LDL were significantly lower in the malaria patients than in the control group at one month after treatment. Most lipid levels had increased at six months while triglyceride levels continued to be lower than normal parameters [35]. These findings contrast with findings from a study in travellers with malaria; both LDL and plasma triglyceride concentrations were normalized at follow up after 2 weeks [15]. In a paediatric study, TC and HDL were still decreased after two weeks, but triglycerides normalized within 14 days. A study with 152 P. vivax patients 


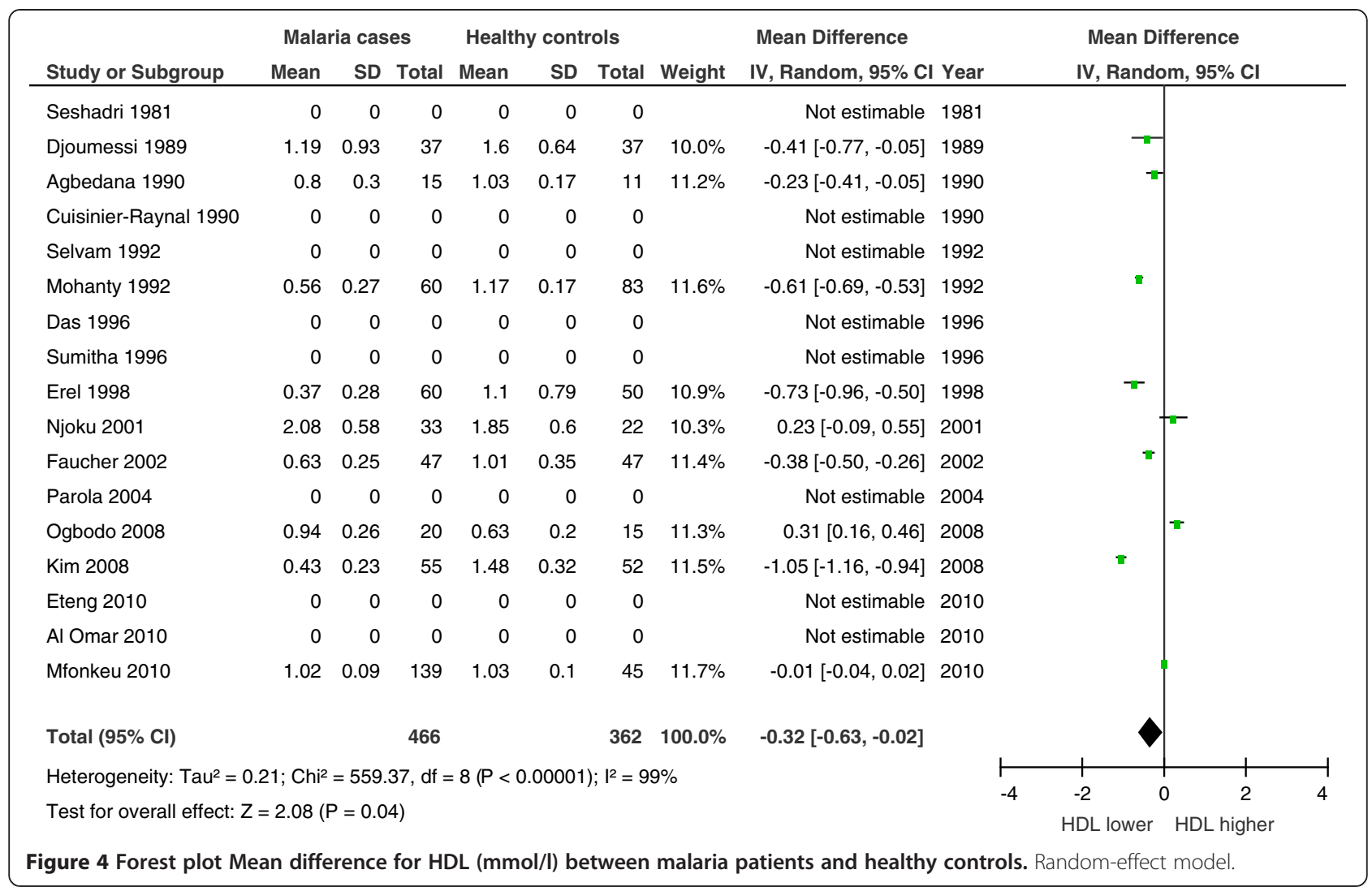

showed that TC, ester and free cholesterol reached normal levels in ten days [46].

\section{Quality assessment and publication bias}

Overall quality assessment scores for risk of bias in studies included in the quantitative analysis ranged from one to five, out of a maximum of five. All studies except one [42] were observational studies. None of them was reported according to all the criteria of the STROBE statement (STrengthening the Reporting of OBservational studies in Epidemiology) [58], a tool in observational studies to prevent bias. In addition, none of the studies that assessed one or more of the lipid profile changes as diagnostic feature of malaria reported the essential information according to the criteria of the STARD statement (STAndards for the Reporting of Diagnostic accuracy studies) [59], a tool to improve the accuracy and completeness of reporting for studies of diagnostic accuracy. Visual assessment of funnel plots showed that the studies were distributed fairly symmetrically about the combined effect size, which suggests little publication bias.

\section{Discussion}

This is the first systematic review and meta-analysis of the impact of malaria on common lipid profile parameters. It confirms previous studies that characteristic serum lipid profile changes occur during malaria. Low serum TC, a low HDL, a low LDL during malaria are described as compared to reference values, healthy and symptomatic controls. Triglycerides were raised during malaria, but this was statistically not significant when compared to symptomatic controls. The conclusion is supported by a similar size and direction of lipid profile changes noted in the records not included in the quantitative synthesis (Additional file 7: Table S1). For IDL cholesterol, VLDL and apolipoproteins, no robust alterations could be observed due to complete absence and paucity, respectively, of studies that measured these laboratory parameters.

The major difficulty regarding the clinically observed serum lipid profile changes is whether they are not only characteristic but truly specific for malaria, rather than a general observed phenomenon that can also be seen in other conditions, particularly (infectious) diseases. Moreover, the association between serum lipid profile changes and malaria is not definitive evidence for the direction of causality, since the existence of confounders, for example, ethnicity, socio-economic status, life-style, food habitats, other infections or diseases, etc., cannot be ruled out and was not corrected for in most of the included studies in this review.

Several arguments support the conclusion that the lipid changes identified are indeed characteristic for malaria and that a causal relationship exists. First of all, 


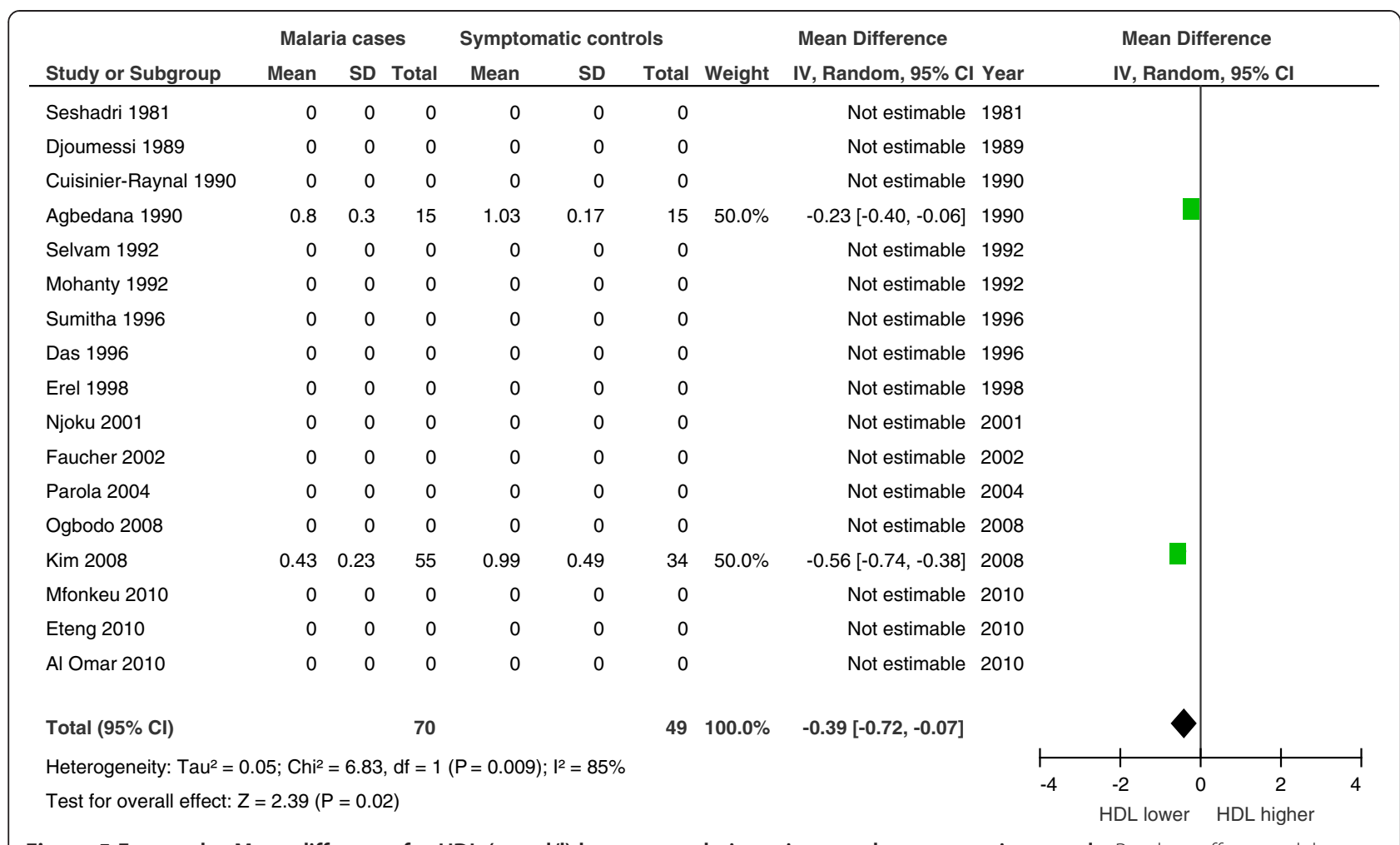

Figure 5 Forest plot Mean difference for HDL $(\mathrm{mmol} / \mathrm{l})$ between malaria patients and symptomatic controls. Random-effect model.

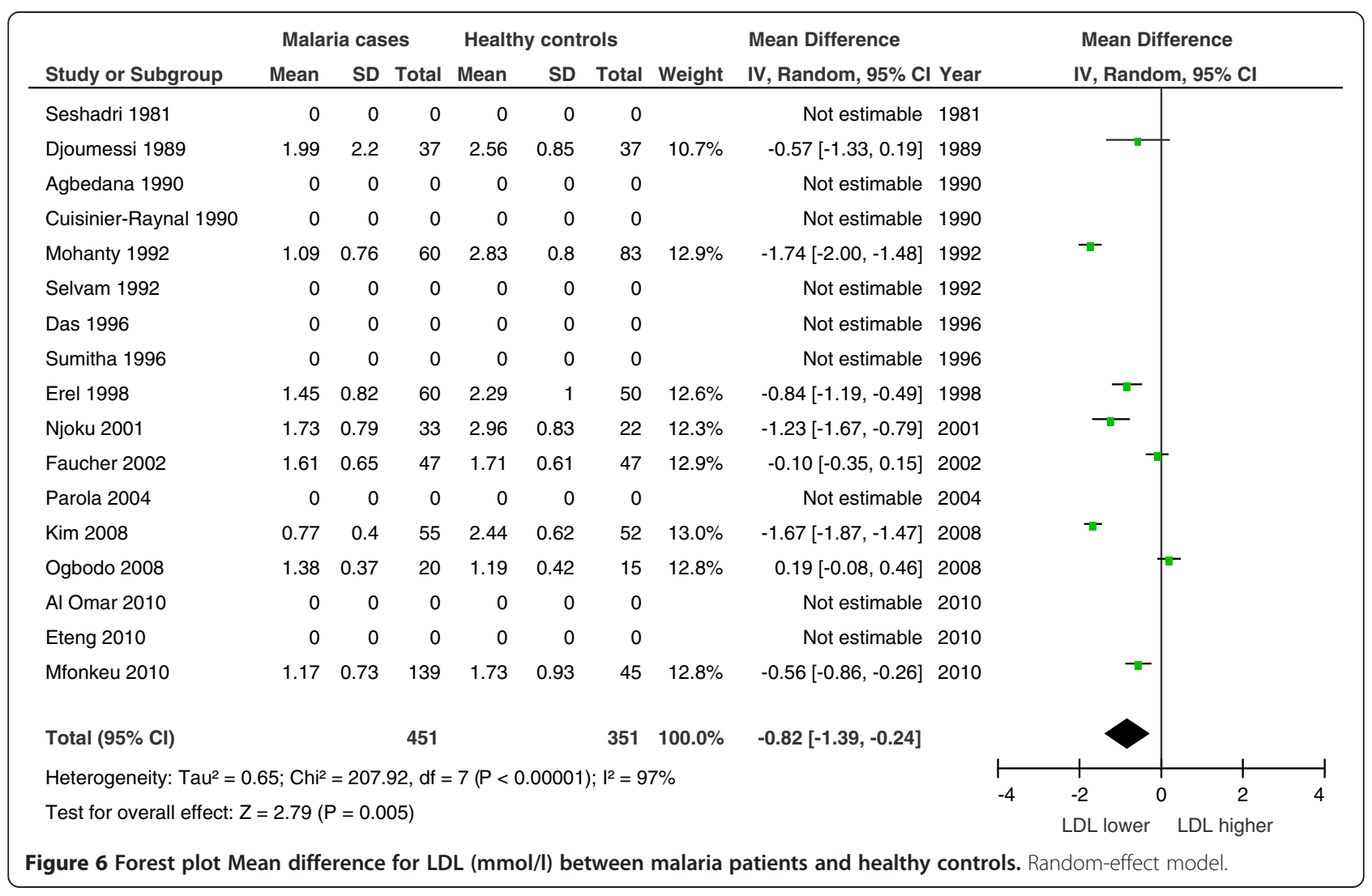




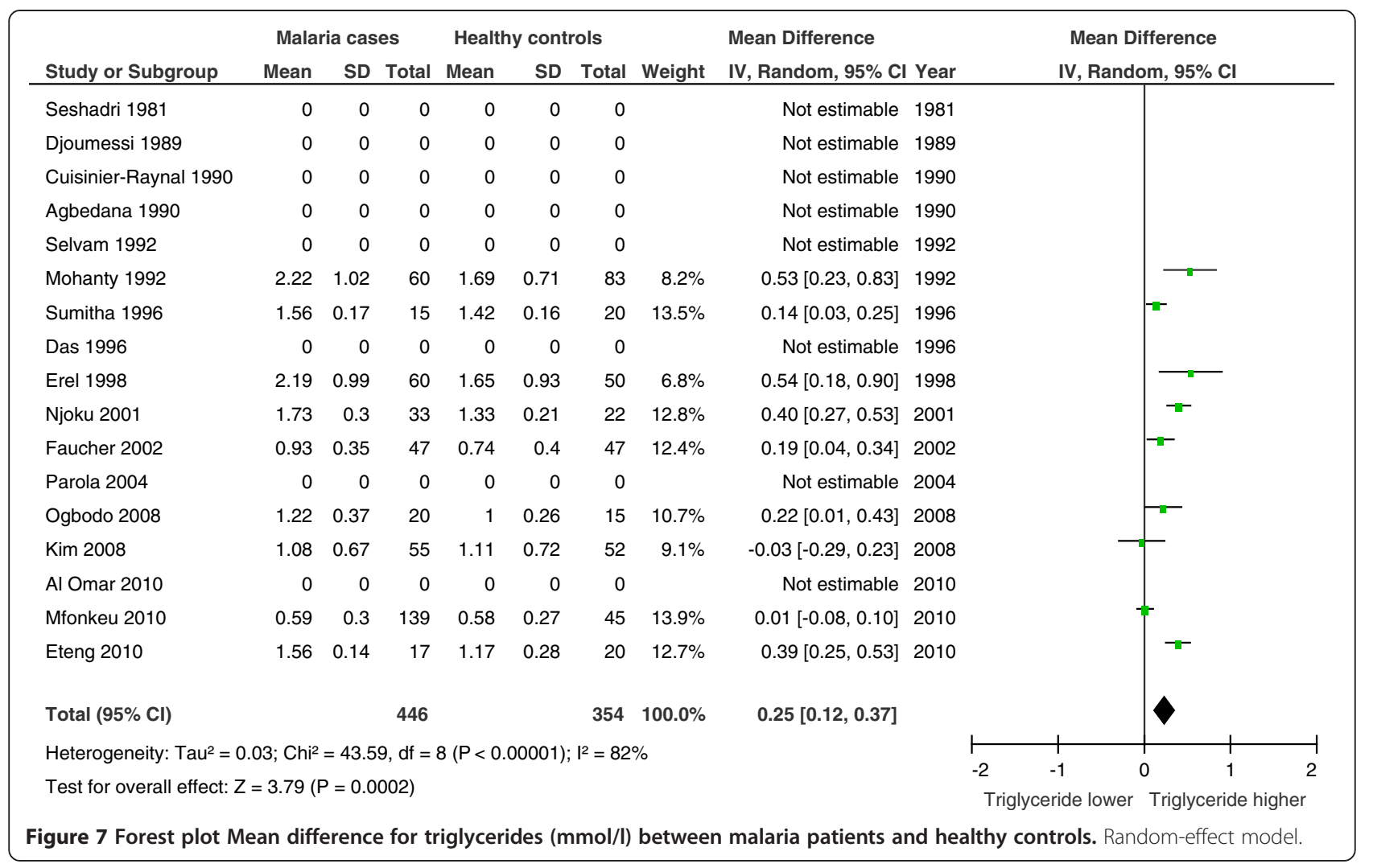

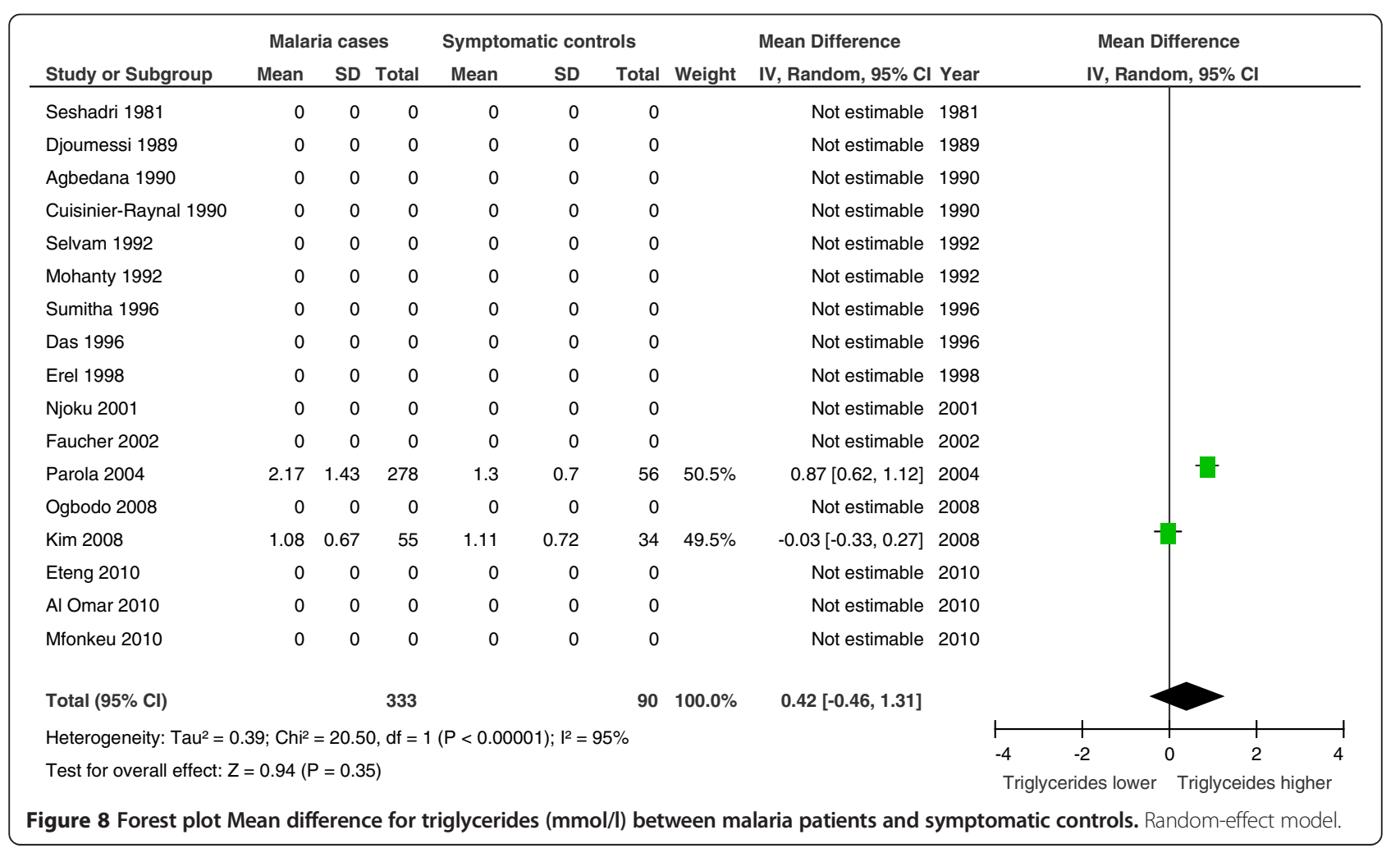


several plausible biological mechanisms are at hand (as discussed in some detail below) that can cause these lipid profile changes in malaria patients. Secondly, consistent findings observed by different researchers in different places with different samples are provided in this review (see Additional file 7: Table S1). The fact that data represent studies that included local inhabitants as well as nonimmune travellers returning from the tropics, both adults and children, indicates these findings are not ethnic-, ageor geographically specific but observed in a variety of settings and patients (see Additional file 7: Table S1). Results also suggest that a biological gradient is present as greater exposure (severe malaria) leads to greater incidence of the effect (lipid profile changes), as shown in the stratified analysis for severe and uncomplicated malaria (see Additional file 5). An important pre-requisite for causality is temporality: the lipid profile changes have to occur after malaria. This, however, cannot be concluded from this metaanalysis nor the included studies since the majority of the included studies are cross-sectional (cause and effect measured at one specific point of time) or prospective observational studies with malaria present at the start of the study. Inverse temporality is demonstrated; treatment of malaria allows the lipid parameters to normalize. It remains to be elucidated why prolonged lipid profile changes are observed even after parasites have been cleared.

Since only controlled studies were included in the quantitative synthesis, other non-infectious diseases and genetic factors are probably comparable among groups. This supports lipid profile changes as malaria-characteristic features; however, it does not exclude confounding. To investigate the main confounder, namely other infectious diseases, studies that compare lipid profile changes during malaria with control patients that present with other infectious diseases are pivotal. The meta-analysis (Figures 3, 5 and 8) that included comparisons between malaria patients and symptomatic controls suggests that the observed lipid profile changes are indeed specific for malaria. TC, HDL and LDL concentrations were lower in malaria and other febrile diseases compared to healthy controls, however, the decline was more pronounced and statistically significant during malaria. If these lipid profile changes are characteristic for malaria, one could expect more pronounced lipid alterations in severe malaria compared to uncomplicated malaria; this is confirmed by three studies $[12,30,42]$. Biological mechanisms of lipid profile changes may be partly host-related, i.e., related to an acute phase reaction [18] or parasite-related [20] or a combination of these two.

\section{Host-related lipid profile changes}

Transient plasma lipid profile changes are not only observed during malaria, but also in other acute diseases [60,61]. Typically, HDL and LDL cholesterol levels are slightly reduced, and VLDL levels may be increased. Several researchers demonstrated low cholesterol levels in acute conditions such as surgical trauma [62], malignancy [63], burns [64] and ischemic heart disease [18]. Hence the changes in plasma lipoproteins appear to form part of the acute-phase reaction and can, at least partially, be ascribed to extravasation due to increased capillary permeability [65]. In addition, a decrease of TC and triglycerides has been reported in patients admitted with an acute infection [66,67]. In a study with critically ill patients, the mean HDL level was significantly lower in patients with an infection compared to patients without infection [68]. The TC levels seemed to be slightly lower and triglycerides higher in infected patients, but these differences were not statistically significant [68].

Various forms of lipid disorders have been associated with acute and chronic infectious diseases of different aetiologies: bacterial, viral and parasitological [69-71]. In human immunodeficiency virus (HIV) infection an increase in the levels of triglycerides and reduced levels of cholesterol, HDL-c and LDL-c [72-74] have been observed. Moreover, the treatment of HIV with highactivity, anti-retroviral therapy (HAART) can cause a more atherogenic lipid profile by increased TC, LDL-c and triglycerides [75]. Hypertriglyceridemia has been described in several diseases with haemophagocytosis.

Hypocholesterolaemia has also been described in various haematological diseases [76], including thalassaemia major [77], thalassaemia intermedia [78], sickle cell disease [79], glucose-6-phosphate dehydrogenase (G6PD) deficiency [80], spherocytosis [81], and aplastic anaemia [82]. It can also accompany anaemia with high erythropoietic activity [83]. The pathophysiology of the lowered cholesterol levels in these diseases remains obscure, although several mechanisms have been proposed, including the dilution of serum due to anaemia; increased cholesterol needs associated with erythroid hyperplasia; macrophage activation with the release of cytokines; increased cholesterol uptake by the reticulo-endothelial system; and liver injury secondary to iron overload [83].

\section{Pathophysiological pathways of lipids during malaria}

Lipids are synthesized in the liver, which incidentally happens to be the site where infective malaria sporozoites travel through the bloodstream, invade and take up residence in the hepatocytes. In this asymptomatic 'exoerythrocytic stage' these cells divide until many mature tissue schizonts are formed, each containing thousands of merozoites. The liver schizonts rupture after days and release these merozoites into the bloodstream, initiating the 'erythrocytic stage'. Within the erythrocyte, a single merozoite divides into eight to 32 merozoites, which demands a considerable amount of lipids (e g, cholesterol) for their anabolic requirements such as membrane formation. The 
capacity of Plasmodium spp. to replicate is noteworthy, achieving one of the fastest growth rates among eukaryotic cells [84]. Malaria parasites are intracellular protozoans, auxotrophic and unable to synthesize organic nutrients required for their growth. To ensure their survival and propagation, they must exchange nutrients over the parasitophorous vacuolar membrane (PVM) [85], which surrounds the parasite [86,87]. This PVM neither acidifies nor fuses with organelles of the endocytic cascade and exocytic pathway and is thus actually completely isolated from the host cell vesicular transport system [88].

Keeping this in view, the following questions arise. First, what is the relation between malaria parasites and lipid synthesis in the liver - are malaria parasites capable to produce essential lipids themselves or are host lipids required? Second, does the malaria parasite benefit from high or low serum lipids in the host environment?

In order to meet the nutrients to rapidly multiply within hepatocytes, but more importantly, red blood cells, malaria parasites must scavenge host cell nutrients they cannot synthesize. Plasmodium spp. cannot synthesize cholesterol itself [89], similar to other intracellular pathogens. These pathogens most often possess the ability to access this lipid from the exogenous or endogenous pathway of the host [90-93]. Also, no biological pathway involved in sterol production can be demonstrated in Plasmodium spp. genome databases [94]. It must be said, however, that morphological data suggest that the parasitophorous vacuole of malaria liver forms does contain sterols [95].

Recent findings demonstrate that the Plasmodium genome includes gene-encoding enzymes for phospholipids metabolism [96], allowing de novo synthesis of phosphatidylcholine via the Kennedy Pathway (de novo synthesis of phosphatidylethanolamine and phosphatidylcholine) and necessitating only the uptake of the small choline molecule [88]. This is important, because these two account for more than $50 \%$ of the total phospholipid species in eukaryotic membranes and thus play a major role in the structure and function of those membranes [97]. Moreover, the genome of $P$. falciparum has genes similar to those encoding for the type II fatty acid synthesis pathway in humans. The type II fatty acid synthetic pathway is the principal route for the production of membrane phospholipidacyl chains [98]. These particular genes are embedded within the apicoplast [99], and aid the production of fatty acids, some of which are unique for Plasmodium spp. [88]. Therefore, Plasmodium spp. might be able to meet several of its lipid needs from its own biological pathways, even if specific extracellular lipids are necessary for in vitro growth [96]. The presence of cholesterol in apicoplast membranes was shown only recently [100].

However, the inability of Plasmodium to stock up host molecules makes a continuous supply of nutrients to the parasite necessary [94]. Probably, this is one of the reasons that malaria parasites choose hepatocytes, as they have unique metabolic properties and are especially efficient in internalizing transport proteins (e. g, lipoproteins) via membrane receptors and are proficient at metabolizing different compounds (e. g, glucose, lipids etc.) in relatively huge quantities [101-104].

A recent study shows that Plasmodium divert cholesterol from the hepatocyte cell until the release of merozoites. Removal of plasma lipoproteins in vitro resulted in a $70 \%$ reduction of cholesterol content in hepatic merozoites [94]. It was discovered that Plasmodium spp. (P. yoelii and P. berghei) salvage cholesterol that had been internalized by LDL. However, reduced expression of host LDL receptors did not influence liver stage burden. Plasmodium is also capable of seizing cholesterol produced by hepatocytes. Pharmacological blockade of host squalene synthase (an enzyme involved in the first step in sterol synthesis) or the down-regulation of the expression of this enzyme by $80 \%$ diminished the cholesterol content of merozoites without effect on parasite development [94]. These data suggest that malaria parasites do need sterols for effective replication, but can also adapt to cholesterol-restrictive conditions by using alternative sources in hepatocytes to maintain infectivity [94]. Another study demonstrated that HDL is essential for the maintenance of $P$. falciparum in in vitro culture $[105,106]$. At relatively low concentrations $(0.75 \mathrm{mg} / \mathrm{ml}$ protein) HDL is able to aid parasite growth and reinvasion in a serum-free system. In higher concentrations $(2.4 \mathrm{mg} / \mathrm{ml}$ protein), HDL is toxic to the parasite within infected erythrocytes after invasion, causing abnormal maturation and death of trophozoites [105]. Late ring-stage parasites at a parasitaemia of $2 \%$ were cultured with HDL or with phosphate buffer (controls). In the HDL-treated group, unfit parasites developed with reduced size, irregular shape, increasing stain density, and haemozoin (malaria pigment) outside the food vacuole [105]. Both host cholesterol synthesized in the endoplasmic reticulum as well as LDL-derived cholesterol are co-transported to the parasitophorous vacuole. Most probably, compensatory activity of the endogenous and exogenous pathways to provide cholesterol to the parasite exists. Furthermore, the parasite could also cause a hypocholesterolaemia in malaria because it utilizes another pathway, that of receptor-mediated endocytosis [107] where cholesterol is extracted from the blood.

\section{Host lipids in the formation of haemozoin}

Besides the role of lipids in the proliferation and metabolism of the parasite, host lipids have also been implicated in the formation of haemozoin in vivo $[108,109]$. Earlier, it has been shown that linoeic acid (a polyunsaturated fatty acid) may be necessary for the dimerization 
of ferriprotoporphyrin IX (a toxic compound released after the digestion of haemoglobin), the initial step in the production of haemozoin [110]. Haemozoin is the end product of the plasmodial detoxification of free haem that is produced by haemoglobin degradation [20]. Historically, it was thought that haemozoin was an inert waste product of the malaria parasite. However, recent research resulted in the recognition of the importance of haemozoin in different aspects of malaria [20,111,112]. Haem crystalization is the target of the widely used antimalarial aminoquinoline drugs [113]. Moreover, not only does the haemozoin production require host lipids, but it appears also that the inhibition of host monocyte functions, one of the eminent immune-modulating haemozoin effects, is caused by hydroxyl fatty acids, generated by Plasmodium spp. in large amounts in the human hosts. The lipid hypothesis postulates that haemozoin formation occurs most rapidly at lipid-water interfaces. In the past 3 three years, convincing evidence is emerging in favour of the lipid model. First, the lipid environments in a parasitized erythrocyte using Nile Red (a lipophilic stain), were characterized [114]. Neutral lipids associated with the digestive vacuole of the parasite were observed. These were composed of di- and triacylgycerols (triglycerides); possibly storage organelles for lipid intermediates produced during the degradation of phospholipids in the food vacuole. Mono-, di- and triacylglycerol heterogeneous mixtures promote haemozoin formation, implying that these neutral lipids are involved in haem detoxification [114]. It was demonstrated that triglycerides are a major lipid portion stored in lipid droplets in the late trophozoite and schizont stage of $P$. falciparum. Besides haem detoxification, it may be utilized to store acryl groups for phospholipid synthesis, glycosyl phosphatidyl inositol (a glycolipid) synthesis, and possibly for beta-oxidation (the process by which fatty acid molecules are broken down in the mitochondria to generate acetyl-coA) [115]. Second, another study demonstrated that in the unrelated haemozoin-forming organisms Schistosoma mansoni, and in the kissing bug, Rhodnius prolixus (triatomine vector of Chagas disease), haemozoin formation occurs inside lipid droplet-like particles or in close association to phospholipid membranes (both hydrophobic environments) [116]. Third, it has been reported that the intracellular mechanism of molecular initiation of haemozoin formation occurs within neutral lipid predominant nanospheres, which envelop haemozoin inside $P$. falciparum digestive vacuoles. It was suggested that haemozoin is formed at the interface between the aqueous medium of the food vacuole and the lipid nanospheres [113]. Another study confirmed these findings, as molecular dynamic simulation showed that a precursor haemozoin dimer forms spontaneously in the absence of the competing hydrogen bonds of water, demonstrating that this substance probably self-assembles near a lipid/water interface in vivo. Probably, haemozoin nucleation occurs at the digestive vacuole inner membrane, with crystallizations occurring in the aqueous rather than lipid phase, as indicated by cryogenic soft X-ray tomography [117-120]. Thus, lipids mediate synthetic haemozoin formation very efficiently. Further weight is added to this lipid hypothesis by another recent study that demonstrated that haemozoinassociated neutral lipids alone are capable of mediating haemozoin formation at adequate rates under physiologically realistic conditions of ion concentrations to account for haemozoin formation [121]. The combination of these recent insights makes a compelling case for the theory that lipids drive haemozoin assembly.

\section{Strengths and limitations}

This review triangulates data from quantitative, qualitative and mixed method studies to increase the content validity and comprehensiveness of the review; however, it does not attempt a full analysis of pathophysiological qualitative data [122]. The meta-analysis of lipid parameters was used to explore the effect of malaria between studies and to provide a pooled analysis to support the findings of the narrative (interpretive) synthesis.

A limitation of this meta-analysis is the statistical heterogeneity of the included studies [123,124]. Therefore, random effect models were used. This was possible as the included studies were clinically comparable (see Additional file 7: Table S1) and on visual inspection of the graphs the individual trial effects were in the same direction within the majority overlapping confidence intervals [125]. The statistical heterogeneity in the results is a consequence of clinical or methodological diversity, or both, among the included studies. In particular, the heterogeneity may be due to differences between subgroups of studies. Also, data extraction errors are a common cause of substantial heterogeneity in results with continuous outcomes [23]. However, these were minimized by double-checking in the data extraction process. Clinical variation may have resulted in heterogeneity most obviously, patient characteristics. Also, varying precision of the measurements of lipid parameters in the included studies can have contributed to heterogeneity, although these are unlikely to have fully accounted for heterogeneity in the study design. Significant statistical heterogeneity arising from methodological diversity or differences in outcome measurements suggests that the included studies are not all estimating the same quantity, but does not necessarily suggest that the true malaria effect on lipid parameters varies. In particular, heterogeneity associated solely with methodological diversity would indicate the studies suffer from different degrees of bias, which is the case (see Additional file 3). Nevertheless, as 
none of the confidence intervals contain zero (except the comparison for the outcome triglycerides with symptomatic controls), there is strong evidence that on average there are malaria-specific effects on common lipid profile parameters.

Another limitation is the poor-to-moderate quality of the studies included in this review, which results from the nature of the study design (some observational studies included healthy controls, some controls with other infectious diseases and some did not include controls at all) and incomplete reporting of essential data (randomization procedures, etc.). However, the consistency of results across studies and settings suggest that the findings of lowered TC, HDL and LDL in patients with malaria are robust.

Reference values of lipid parameters may vary widely between countries and populations, however, they did not influence the results since only mean differences were used in the meta-analysis.

The probability of publication bias was judged as substantial. The funnel plots did not identify publication bias. However, it must be noted that, as a rule of thumb, tests for funnel plot asymmetry should be used with confidence only when there are at least ten studies included in the meta-analysis, because when there are fewer studies the power of the tests is too low to distinguish chance from real asymmetry. This was only the case for funnel plot 1 in the review.

For the literature review, the main limitation was the fact that unpublished studies were not searched for, which may have introduced bias [126]. However, by searching clinical trial registries for ongoing or unpublished studies, this risk of bias was considerably diminished [127]. Whilst no restrictions were placed on the language of publication [128], and no studies were excluded on the basis of language, the focus of the majority of the used search engines (Medline/PubMed being the primary source of studies) to date has been on the European family of languages, and predominantly English. Unfortunately one record [57], published in an Indian medical journal, could not be retrieved despite considerable efforts (contacting the author(s), as well as several European libraries). This, however, does not influence the results since the record would not have been included in the quantitative synthesis anyway.

\section{Conclusion}

Particular serum lipid profile changes are a characteristic feature of malaria. Several hypotheses can explain the underlying biological mechanisms. This review highlights the need for further research into these biological pathways, which can provide new knowledge on the pathogenesis of malaria, and thus open avenues to explore novel anti-malarial interventions. For example, an observational study relating these characteristics of the malaria-specific pathogen-host interplay to the amount of haemozoin produced by human-pathogenic Plasmodium.

\section{Additional files}

Additional file 1: Protocol systematic review. Following the PRISMA
guidelines, a protocol for the systematic review was drafted in advance.
The documents provides the objectives and proposed search strategies
for this systematic review and meta-analysis.

Additional file 2: Search strategies. In this document, all information sources are described including databases with dates of coverage, detailed search strategies, and the last search date.

Additional file 3: Risk-of-bias assessments. Document with risk of bias assessments for the quality of non-randomized studies included in this meta-analysis.

Additional file 4: Statistical analysis. The data provided describes the statistical analysis including the inverse-variance methods for combining results across studies (the meta-analysis), calculation of pooled mean and standard deviation and rounding of the data.

Additional file 5: Stratified meta-analysis for uncomplicated and severe malaria. Document providing results of the meta-analysis (total cholesterol) stratified for uncomplicated malaria and severe malaria.

Additional file 6: Forest plots \& funnel plots. The data provided describes the full results of the meta-analysis for the different lipid parameters investigated. To increase transparency, both fixed and random effect analyzes are shown in this document.

Additional file 7: Table S1. Studies included in the systematic review and meta-analysis.

Additional file 8: Forest plots without the study of Faucher et al. The data provided describes the results of the meta-analysis for the different lipid parameters investigated without one study with a control group consisting of (very) low parasitaemia malaria patients.

\section{Abbreviations}

HDL: High-density lipoprotein; LDL: Low-density lipoprotein;

IDL: Intermediate-density lipoprotein; VLDL: Very-low density lipoprotein;

TC: Total cholesterol; TG/TAG: Triglycerides; Hz: Haemozoin;

PVM: Parasitophorous vacuolar membrane; PRISMA: Preferred Reporting

Items for Systematic Reviews and Meta-Analyses; MOOSE: Meta-analysis Of

Observational Studies in Epidemiology.

\section{Competing interests}

The authors declare that they have no competing interests.

\section{Authors' contributions}

MPG, BJV and RWW conceived the study. BJV, RWW and MPG developed the study design and the outline of the report. IMN and BJV searched the scientific literature and BJV prepared the first draft of the report. BJV and RWW performed the statistical analyses. RWW, IMN and MPG contributed to the outline of the report. All authors read and approved the final manuscript.

\section{Acknowledgement}

We thank Thomas Hänscheid (Professor of Microbiology at the Instituto de Microbiologia, Faculdade de Medicina de Lisboa, Portugal) for critically reviewing the manuscript. We also thank the reviewers for their valuable comments and suggestions.

\section{Funding}

International Society of Travel Medicine (ISTM) Research Award, 2012.

\section{Author details}

${ }^{1}$ Centre of Tropical Medicine and Travel Medicine, Department of Infectious Diseases, Academic Medical Centre, University of Amsterdam, Meibergdreef 9, PO Box 226601100 DD, Amsterdam, The Netherlands. ${ }^{2}$ Centre de Recherches Médicales de Lambaréné (CERMEL), Lambaréné, Gabon. ${ }^{3}$ Medical 
Library, Academic Medical Centre, University of Amsterdam, Amsterdam, The Netherlands. ${ }^{4}$ Institute of Tropical Medicine, University of Tübingen,

Tübingen, Germany.

Received: 13 September 2013 Accepted: 4 December 2013

Published: 7 December 2013

\section{References}

1. Lambrecht AJ, Snoeck J, Timmermans U: Transient an-alphalipoproteinaemia in man during infection by Plasmodium vivax. Lancet 1978, 1:1206.

2. Angus MGN, Fletcher KA, Maegraith BG: Studies on the lipids of Plasmodium knowlesi infected rhesus monkeys (Macaca mulatta). IV. Changes in erythrocyte lipids. Ann Trop Med Parasitol 1971, 65:429-439.

3. Angus MGN, Fletcher KA, Maegraith BG: Studies on the lipids of Plasmodium knowlesi infected rhesus monkeys (Macaca mulatta). III: Changes in liver lipids. Ann Trop Med Parasitol 1971, 65:419-427.

4. Angus MGN, Fletcher KA, Maegraith BG: Studies on the lipids of Plasmodium knowlesi infected rhesus monkeys (Macaca mulatta). II. Changes in serum nonesterified fatty acids. Ann Trop Med Parasitol 1971, 65:155-167.

5. Chagnon A, Guiguen Y, Sutre E: Hypocholesterolemia in malaria: an aid to diagnosis? Semaine des Hopitaux 1985, 61:2075-2076.

6. Maurois P, Vernes A, Charet P, Nouvelot A, Becquet R, Giard R: Changes in serum lipoproteins during malariatherapy with Plasmodium vivax. Ann Trop Med Parasitol 1979, 73:491-493.

7. Seshadri C, Shetty BR, Gowri N, Venkataraghavan S, Chari MV: Serum cholesterol and total lipids in Plasmodium vivax malaria-a preliminary study. Indian J Med Res 1981, 74:513-516.

8. Vernes A, Dei CE, Dutoit E, Maurois P, Gentilini JL, Biguet J: [Changes of serum lipoproteins during the course of human malaria] (in French). Pathol Biol (Paris) 1980, 28:457-460.

9. Cuisinier-Raynal JC, Bire F, Clerc M, Bernard J, Sarrouy J: [Human malaria: dysglobulinemia-hypocholesterolemia syndrome] (in French). Med Trop (Mars) 1990, 50:91-95

10. Faucher JF, Ngou-Milama E, Missinou MA, Ngomo R, Kombila M, Kremsner PG: The impact of malaria on common lipid parameters. Parasitol Res 2002, 88:1040-1043.

11. Davis TM, Sturm M, Zhang YR, Spencer JL, Graham RM, Li GQ, Taylor RR: Platelet-activating factor and lipid metabolism in acute malaria. J Infect 1993, 26:279-285.

12. Mohanty S, Mishra SK, Das BS, Satpathy SK, Mohanty D, Patnaik JK, Bose TK: Altered plasma lipid pattern in falciparum malaria. Ann Trop Med Parasitol 1992, 86:601-606.

13. Kittl EM, Diridl G, Lenhart V, Neuwald C, Tomasits J, Pichler H, Bauer K: [HDL cholesterol as a sensitive diagnostic parameter in malaria] (in German). Wien Klin Wochenschr 1992, 104:21-24.

14. Baptista JL, Vervoort T, van der Stuyft P, Wery M: [Changes in plasma lipid levels as a function of Plasmodium falciparum infection in Sao Tome] (in French). Parasite 1996, 3:335-340.

15. Nilsson-Ehle I, Nilsson-Ehle P: Changes in plasma lipoproteins in acute malaria. J Intern Med 1990, 227:151-155.

16. Badiaga S, Barrau K, Parola P, Brouqui P, Delmont J: Contribution of nonspecific laboratory test to the diagnosis of malaria in febrile travelers returning from endemic areas: value of hypocholesterolemia. J Travel Med 2002, 9:117-121.

17. Khovidhunkit W, Kim MS, Memon RA, Shigenaga JK, Moser AH, Feingold KR, Grunfeld C: Effects of infection and inflammation on lipid and lipoprotein metabolism: mechanisms and consequences to the host. J Lipid Res 2004, 45:1169-1196.

18. Rosenson RS: Myocardial injury: the acute phase response and lipoprotein metabolism. J Am Coll Cardiol 1993, 22:933-940.

19. Maurois $P$, Vernes $A$, Charet $P$, Deicas E: Transient changes in serum lipoproteins during antimalarial therapy and malaria. Lancet 1978, 2:629.

20. Hanscheid T, Egan TJ, Grobusch MP: Haemozoin: from melatonin pigment to drug target, diagnostic tool, and immune modulator. Lancet Infect Dis 2007, 7:675-685

21. Holz JGG: Lipids and the malaria parasite. Bull World Health Organ 1977, 55:237-248

22. Berman NG, Parker RA: Meta-analysis: neither quick nor easy. BMC Med Res Methodol 2002, 2:10.
23. Liberati A, Altman DG, Tetzlaff J, Mulrow C, Gotzsche PC, loannidis JP, Clarke M, Devereaux PJ, Kleijnen J, Moher D: The PRISMA statement for reporting systematic reviews and meta-analyses of studies that evaluate health care interventions: explanation and elaboration. PLoS Med 2009, 6:e1000100.

24. Moher D, Altman DG, Liberati A, Tetzlaff J: PRISMA statement. Epidemiology 2011, 22:128.

25. Stroup DF, Berlin JA, Morton SC, Olkin I, Williamson GD, Rennie D, Moher D, Becker BJ, Sipe TA, Thacker SB: Meta-analysis of observational studies in epidemiology: a proposal for reporting. Meta-analysis Of Observational Studies in Epidemiology (MOOSE) group. JAMA 2000, 283:2008-2012.

26. ClinicalTrials.gov - U.S: National Institutes of Health. 2013. http://www.clinicaltrials.gov/.

27. Current Controlled Trials; 2013. http://www.controlled-trials.com/.

28. Egger M, Davey SG, Schneider M, Minder C: Bias in meta-analysis detected by a simple, graphical test. BMJ 1997, 315:629-634.

29. Guyatt GH, Oxman AD, Montori V, Vist G, Kunz R, Brozek J, Alonso-Coello P, Djulbegovic B, Atkins D, Falck-Ytter Y, Williams JW Jr, Meerpohl J, Norris SL, Akl EA, Schünemann HJ: GRADE guidelines: 5 . Rating the quality of evidence-publication bias. J Clin Epidemiol 2011, 64:1277-1282

30. Mfonkeu JB, Gouado I, Kuate HF, Zambou O, Combes V, Grau GE, Zollo PH: Biochemical markers of nutritional status and childhood malaria severity in Cameroon. Br J Nutr 2010, 104:886-892.

31. Das BS, Thurnham DI, Das DB: Plasma alpha-tocopherol, retinol, and carotenoids in children with falciparum malaria. Am J Clin Nutr 1996, 64:94-100.

32. Chukwuocha UM, Eke KN: Malaria parasite status and cholesterol level of malaria patients in parts of the IMO River Basin of Nigeria. Asian Pac J Trop Med 2011, 4:993-996.

33. Erel $\mathrm{O}$, Kocyigit A, Bulut $\mathrm{V}$, Avci S, Aktepe $\mathrm{N}$ : Role of lipids, lipoproteins and lipid peroxidation in thrombocytopenia in patients with vivax malaria. Haematologia (Budap) 1998, 29:207-212.

34. Grobusch MP, Krull M, Teichmann D, Gobels K, Suttorp N: Falciparum malaria and Tangier disease. Int J Infect Dis 2003, 7:74-75.

35. Kim JS, Oh JS, Chang EA, Bae SY, Nam DH, Lee CH, Kim HC, Klein TA, Lim CS, Kim YK: Alteration of platelet counts and lipid profiles after treatment of acute Plasmodium vivax. Acta Trop 2008, 106:39-43.

36. Ngou-Milama E, Duong TH, Minko F, Dufillot D, Kombila M, Richard-Lenoble D, Mouray H: [Lipid profile during specific malaria therapy in Gabonese children] (in French). Sante 1995, 5:95-99.

37. Parola P, Gazin P, Patella F, Badiaga S, Delmont J, Brouqui P. Hypertriglyceridemia as an indicator of the severity of falciparum malaria in returned travelers: a clinical retrospective study. Parasitol Res 2004, 92:464-466.

38. Djoumessi S: Serum lipids and lipoproteins during malaria infection. Pathol Biol (Paris) 1989, 37:909-911.

39. Onongbu IC, Onyeneke EC: Plasma lipid changes in human malaria. Tropenmed Parasitol 1983, 34:193-196.

40. Sumitha K, Ravichandiran K, Selvam R: Blood lipid changes in repeated infections of vivax malaria. Indian J Malariol 1996, 33:131-138.

41. Krishna AP, Chandrika, Kumar S, Acharya M, Patil SL: Variation in common lipid parameters in malaria infected patients. Indian J Physiol Pharmacol 2009, 53:271-274.

42. Njoku OU, Alumanah EO, Meremikwu CU: Effect of Azadirachta indica extract on plasma lipid levels in human malaria. Boll Chim Farm 2001, 140:367-370.

43. Njoku OU, Ononogbu IC, Nwachukwu DE: Plasma cholesterol, B-carotene and ascorbic acid changes in human malaria. J Commun Dis 1995, 27:186-190.

44. Agbedana EO, Salimonu LS, Taylor GO, Williams Al: Studies of total and high density lipoprotein cholesterol in childhood malaria: a preliminary study. Ann Trop Med Parasitol 1990, 84:529-530.

45. Nicolas X, Nicolas F, Gorge O, Perret JL, Touze JE: [Malaria in expatriates in Africa. 154 cases. Clinical problems and therapeutic difficulties] (in French). Presse Med 1997, 26:158-160.

46. Selvam R, Mathews ST: Biochemical alterations in Plasmodium vivax-infected malarial patients before and after radical treatment. Indian J Malariol 1992, 29:103-111.

47. Ayoola OO, Whatmore A, Balogun WO, Jarrett OO, Cruickshank JK, Clayton PE: Maternal malaria status and metabolic profiles in pregnancy and in cord blood: relationships with birth size in Nigerian infants. Malar J 2012, 11:75 
48. Ramirez-Olivencia G, Herrero MD, Subirats M, De Juanes JR, Pena JM, Puente S: [Imported malaria in adults. Clinical, epidemiological and analytical features] (in Spanish). Rev Clin Esp 2012, 212:1-9.

49. Hansmann $Y$, Staub-Schmidt T, Christmann D: [Malaria brought into Strasbourg: an epidemiological, clinical, biological and therapeutic study] (in French). Trop Med Int Health 1997, 2:941-952.

50. Eteng MU, Ekwe AO, Eyong EU, Ibekwe HA, Abolaji AO, Onwuka FC, Osuchukwu NC, Essien NC: Biochemical and haematological changes in pregnant malaria patients and pregnant non-malaria women. Sci Res Essays 2010, 5:1009-1013.

51. Alencar FH, Yuyama LKO, Gutierrez MEL: [Nutritional and dietary status of individuals with malaria resident in Amazonas State - Brazil] (in Portuguese). Acta Amazon 2001, 31:227-236.

52. Ogbodo SO, Ogah O, Obu HA, Shu EN, Afiukwa C: Lipid and lipoprotein levels in children with malaria parasitaemia. Curr Pediatr Res 2008, 12:13-17.

53. Ozkaya G, Yildirim T, Aydin K, Erguven S, Unal S: [A Plasmodium falciparum malaria case originated from Mozambique: clues for the diagnosis and therapy] (in Turkish). Mikrobiyol Bul 2006, 40:407-411.

54. Al-Omar IA, Eligail AM, Al-Ashban RM, Shah AH: Effect of falciparum malaria infection on blood cholesterol and platelets. J Saudi Chem Soc 2010 14:83-89.

55. Blair S, Carmona J, Correa A: [Malaria in children: links between nutrition and immunity] (in Spanish). Rev Panam Salud Publica 2002, 11:5-14.

56. Vinoth PN, Thomas KA, Selvan SM, Suman DF, Scott JX: Hemophagocytic syndrome associated with Plasmodium falciparum infection. Indian $J$ Pathol Microbiol 2011, 54:594-596.

57. D'Souza B, Ruby B, Alap C, Sohil T, Chakrapani M, Vinodchandran Ashok PK et al: Influence of malaria on high density lipoprotein cholesterol and total cholesterol/HDL cholesterol ratio in two cases of diabetes mellitus. Biomedicine (India) 2012, 32:440-442.

58. von EE, Altman DG, Egger M, Pocock SJ, Gotzsche PC, Vandenbroucke JP The Strengthening the reporting of observational studies in epidemiology (STROBE) statement: guidelines for reporting observational studies. Lancet 2007, 370:1453-1457.

59. Bossuyt PM, Reitsma JB, Bruns DE, Gatsonis CA, Glasziou PP, Irwig LM, Moher D, Rennie D, de Vet HC, Lijmer JG, Standards for Reporting of Diagnostic Accuracy Group: The STARD statement for reporting studies of diagnostic accuracy: explanation and elaboration. The Standards for Reporting of Diagnostic Accuracy Group. Croat Med J 2003, 44:639-650.

60. Luthold S, Berneis K, Bady P, Muller B: Effects of infectious disease on plasma lipids and their diagnostic significance in critical illness. Eur J Clin Invest 2007, 37:573-579.

61. van Leeuwen HJ, Heezius EC, Dallinga GM, van Strijp JA, Verhoef J, van Kessel KP: Lipoprotein metabolism in patients with severe sepsis. Crit Care Med 2003, 31:1359-1366

62. Akgun S, Ertel NH, Mosenthal A, Oser W: Postsurgical reduction of serum lipoproteins: interleukin- 6 and the acute-phase response. J Lab Clin Med 1998, 131:103-108

63. Budd D, Ginsberg H: Hypocholesterolemia and acute myelogenous leukemia. Association between disease activity and plasma low-density lipoprotein cholesterol concentrations. Cancer 1986, 58:1361-1365.

64. Coombes EJ, Shakespeare PG, Batstone GF: Lipoprotein changes after burn injury in man. J Trauma 1980, 20:971-975.

65. Stubbe I, Gustafson A, Nilsson-Ehle P: Alterations in plasma proteins and lipoproteins in acute myocardial infarction: effects on activation of lipoprotein lipase. Scand J Clin Lab Invest 1982, 42:437-444.

66. Alvarez C, Ramos A: Lipids, lipoproteins, and apoproteins in serum during infection. Clin Chem 1986, 32:142-145.

67. Sammalkorpi K, Valtonen V, Kerttula Y, Nikkila E, Taskinen MR: Changes in serum lipoprotein pattern induced by acute infections. Metabolism 1988, 37:859-865.

68. Gordon BR, Parker TS, Levine DM, Saal SD, Wang JC, Sloan BJ, Barie PS, Rubin AL: Low lipid concentrations in critical illness: implications for preventing and treating endotoxemia. Crit Care Med 1996, 24:584-589

69. Hoffmeister A, Rothenbacher D, Bode G, Persson K, Marz W, Nauck MA, Brenner $\mathrm{H}$, Hombach V, Koenig W: Current infection with Helicobacter pylori, but not seropositivity to Chlamydia pneumoniae or cytomegalovirus, is associated with an atherogenic, modified lipid profile. Arterioscler Thromb Vasc Biol 2001, 21:427-432.
70. Beisel WR: Impact of infectious disease upon fat metabolism and immune functions. Cancer Res 1981, 41:3797-3798.

71. Feingold KR, Krauss RM, Pang M, Doerrler W, Jensen P, Grunfeld C: The hypertriglyceridemia of acquired immunodeficiency syndrome is associated with an increased prevalence of low density lipoprotein subclass pattern B. J Clin Endocrinol Metab 1993, 76:1423-1427.

72. Grunfeld C, Pang M, Doerrler W, Shigenaga JK, Jensen P, Feingold KR: Lipids, lipoproteins, triglyceride clearance, and cytokines in human immunodeficiency virus infection and the acquired immunodeficiency syndrome. J Clin Endocrinol Metab 1992, 74:1045-1052.

73. Treitinger A, Spada C, da Silva LM, Hermes EM, Amaral JA, Abdalla DS: Lipid and acute-phase protein alterations in HIV-1 infected patients in the early stages of infection: correlation with CD4+ lymphocytes. Braz J Infect Dis 2001, 5:192-199.

74. Hellerstein MK, Grunfeld C, Wu K, Christiansen M, Kaempfer S, Kletke C, Shackleton $\mathrm{CH}$ : Increased de novo hepatic lipogenesis in human immunodeficiency virus infection. J Clin Endocrinol Metab 1993, 76:559-565

75. Duro M, Sarmento-Castro R, Almeida C, Medeiros R, Rebelo I: Lipid profile changes by high activity anti-retroviral therapy. Clin Biochem 2013, 46:740-744.

76. Westerman MP: Hypocholesterolaemia and anaemia. Br J Haematol 1975, 31:87-94.

77. Papanastasiou DA, Siorokou T, Haliotis FA: beta-Thalassaemia and factors affecting the metabolism of lipids and lipoproteins. Haematologia (Budap) 1996, 27:143-153.

78. Hartman C, Tamary H, Tamir A, Shabad E, Levine C, Koren A, Shamir R: Hypocholesterolemia in children and adolescents with beta-thalassemia intermedia. J Pediatr 2002, 141:543-547.

79. Vanderjagt DJ, Shores J, Okorodudu A, Okolo SN, Glew RH: Hypocholesterolemia in Nigerian children with sickle cell disease. J Trop Pediatr 2002, 48:156-161

80. Muntoni S, Batetta B, Dessi S, Muntoni S, Pani P: Serum lipoprotein profile in the Mediterranean variant of glucose-6-phosphate dehydrogenase deficiency. Eur J Epidemiol 1992, 8(Suppl 1):48-53.

81. Johnsson R, Saris NE: Plasma and erythrocyte lipids in hereditary spherocytosis. Clin Chim Acta 1981, 114:263-268.

82. Yokoyama M, Suto $Y$, Sato $H$, Arai $K$, Waga S, Kitazawa J, Maruyama H, Ito E: Low serum lipids suggest severe bone marrow failure in children with aplastic anemia. Pediatr Int 2000, 42:613-619.

83. Shalev H, Kapelushnik J, Moser A, Knobler H, Tamary H: Hypocholesterolemia in chronic anemias with increased erythropoietic activity. Am J Hematol 2007, 82:199-202.

84. Sinnis P, Sim BK: Cell invasion by the vertebrate stages of Plasmodium. Trends Microbiol 1997, 5:52-58.

85. Lingelbach $K$, Joiner KA: The parasitophorous vacuole membrane surrounding Plasmodium and Toxoplasma: an unusual compartment in infected cells. J Cell Sci 1998, 111(Pt 11):1467-1475.

86. Sinai AP, Joiner KA: Safe haven: the cell biology of nonfusogenic pathogen vacuoles. Annu Rev Microbiol 1997, 51:415-462.

87. Kirk K: Membrane transport in the malaria-infected erythrocyte. Physiol Rev 2001, 81:495-537.

88. Vial HJ, Eldin P, Tielens AG, van Hellemond JJ: Phospholipids in parasitic protozoa. Mol Biochem Parasitol 2003, 126:143-154

89. Sherman IW: Biochemistry of Plasmodium (malarial parasites). Microbiol Rev 1979, 43:453-495.

90. Coppens I, Sinai AP, Joiner KA: Toxoplasma gondii exploits host low-density lipoprotein receptor-mediated endocytosis for cholesterol acquisition. J Cell Biol 2000, 149:167-180.

91. Carabeo RA, Mead DJ, Hackstadt T: Golgi-dependent transport of cholesterol to the Chlamydia trachomatis inclusion. Proc Natl Acad Sci USA 2003, 100:6771-6776.

92. Catron DM, Lange Y, Borensztajn J, Sylvester MD, Jones BD, Haldar K: Salmonella enterica serovar Typhimurium requires nonsterol precursors of the cholesterol biosynthetic pathway for intracellular proliferation. Infect Immun 2004, 72:1036-1042

93. Kumar Y, Cocchiaro J, Valdivia RH: The obligate intracellular pathogen Chlamydia trachomatis targets host lipid droplets. Curr Bio/ 2006, 16:1646-1651.

94. Labaied M, Jayabalasingham B, Bano N, Cha SJ, Sandoval J, Guan G, Coppens I: Plasmodium salvages cholesterol internalized by LDL and synthesized de novo in the liver. Cell Microbiol 2011, 13:569-586. 
95. Bano N, Romano JD, Jayabalasingham B, Coppens I: Cellular interactions of Plasmodium liver stage with its host mammalian cell. Int J Parasitol 2007, 37:1329-1341

96. Bansal D, Bhatti HS, Sehgal R: Role of cholesterol in parasitic infections. Lipids Health Dis 2005, 4:10.

97. Gibellini F, Smith TK: The Kennedy pathway-De novo synthesis of phosphatidylethanolamine and phosphatidylcholine. IUBMB Life 2010, 62:414-428.

98. White SW, Zheng J, Zhang YM, Rock: The structural biology of type II fatty acid biosynthesis. Annu Rev Biochem 2005, 74:791-831.

99. MacRae JI, Marechal E, Biot C, Botte CY: The apicoplast: a key target to cure malaria. Curr Pharm Des 2012, 18:3490-3504.

100. Botté CY, Yamaryo-Botté Y, Rupasinghe TW, Mullin KA, MacRae Jl, Spurck TP, Kalanon M, Shears MJ, Coppel RL, Crellin PK, Maréchal E, McConville MJ, McFadden Gl: Atypical lipid composition in the purified relict plastid (apicoplast) of malaria parasites. Proc Natl Acad Sci USA 2013, 110:7506-7511.

101. Morgan EH, Baker E: Iron uptake and metabolism by hepatocytes. Fed Proc 1986, 45:2810-2816.

102. Pels Rijcken WR, Overdijk B, van den Eijnden DH, Ferwerda W: Pyrimidine nucleotide metabolism in rat hepatocytes: evidence for compartmentation of nucleotide pools. Biochem J 1993, 293(Pt 1):207-213.

103. Klover PJ, Mooney RA: Hepatocytes: critical for glucose homeostasis. Int J Biochem Cell Biol 2004, 36:753-758.

104. Nguyen P, Leray V, Diez M, Serisier S, Le BJ, Siliart B, Dumon H: Liver lipid metabolism. J Anim Physiol Anim Nutr (Berl) 2008, 92:272-283.

105. Imrie H, Ferguson DJ, Carter M, Drain J, Schiflett A, Hajduk SL, Day KP: Light and electron microscopical observations of the effects of high-density lipoprotein on growth of Plasmodium falciparum in vitro. Parasitology 2004, 128:577-584

106. Trager W, Jensen JB: Human malaria parasites in continuous culture. Science 1976, 193:673-675.

107. Goldstein JL, Brown MS, Anderson RG, Russell DW, Schneider WJ: Receptormediated endocytosis: concepts emerging from the LDL receptor system. Annu Rev Cell Biol 1985, 1:1-39.

108. Bendrat K, Berger BJ, Cerami A: Haem polymerization in malaria [5]. Nature 1995, 378:138-139.

109. Fitch CD, Cai GZ, Chen YF, Shoemaker JD: Involvement of lipids in ferriprotoporphyrin IX polymerization in malaria. Biochimt Biophys Acta 1999, 1454:31-37.

110. Fitch CD, Chen YF, Cai GZ: Chloroquine-induced masking of a lipid that promotes ferriprotoporphyrin IX dimerization in malaria. J Biol Chem 2003, 278:22596-22599.

111. Frita R, Rebelo M, Pamplona A, Vigario AM, Mota MM, Grobusch MP, Hänscheid T: Simple flow cytometric detection of haemozoin containing leukocytes and erythrocytes for research on diagnosis, immunology and drug sensitivity testing. Malar J 2011, 10:74

112. Rebelo M, Sousa C, Shapiro HM, Mota MM, Grobusch MP, Hänscheid T: A novel flow cytometric hemozoin detection assay for real-time sensitivity testing of Plasmodium falciparum. PLoS One 2013, 8:e61606.

113. Pisciotta JM, Coppens I, Tripathi AK, Scholl PF, Shuman J, Bajad S, Shulaev V, Sullivan DJ Jr: The role of eutral lipid nanospheres in Plasmodium falciparum haem crystallization. Biochem J 2007, 402:197-204.

114. Jackson KE, Klonis N, Ferguson DJP, Adisa A, Dogovski C, Tilley L: Food vacuole-associated lipid bodies and heterogeneous lipid environments in the malaria parasite, Plasmodium falciparum. Mol Microbiol 2004, 54:109-122.

115. Nawabi P, Lykidis A, Ji D, Haldar K: Neutral-lipid analysis reveals elevation of acylglycerols and lack of cholesterol esters in Plasmodium falciparuminfected erythrocytes. Eukaryot Cell 2003, 2:1128-1131.

116. Oliveira MF, Kycia SW, Gomez A, Kosar AJ, Bohle DS, Hempelmann E, Menezes D, Vannier-Santos MA, Oliveira PL, Ferreira ST: Structural and morphological characterization of hemozoin produced by Schistosoma mansoni and Rhodnius prolixus. FEBS Lett 2005, 579:6010-6016.

117. Kapishnikov S, Weiner A, Shimoni E, Guttmann P, Schneider G, DahanPasternak N, Dzikowski R, Leiserowitz L, Elbaum M: Oriented nucleation of hemozoin at the digestive vacuole membrane in Plasmodium falciparum. Proc Natl Acad Sci USA 2012, 109:11188-11193.

118. Kapishnikov S, Berthing T, Hviid L, Dierolf M, Menzel A, Pfeiffer F, Als-Nielsen $J$, Leiserowitz L: Aligned hemozoin crystals in curved clusters in malarial red blood cells revealed by nanoprobe X-ray Fe fluorescence and diffraction. Proc Natl Acad Sci USA 2012, 109:11184-11187.
119. Hoang AN, Sandlin RD, Omar A, Egan TJ, Wright DW: The neutral lipid composition present in the digestive vacuole of Plasmodium falciparum concentrates heme and mediates beta-hematin formation with an unusually low activation energy. Biochemistry 2010, 49:10107-10116.

120. Hoang AN, Ncokazi KK, de Villiers KA, Wright DW, Egan TJ: Crystallization of synthetic haemozoin (beta-haematin) nucleated at the surface of lipid particles. Dalton Trans 2010, 39:1235-1244.

121. Ambele MA, Egan TJ: Neutral lipids associated with haemozoin mediate efficient and rapid beta-haematin formation at physiological $\mathrm{pH}$, temperature and ionic composition. Malar J 2012, 11:337.

122. Dixon-Woods M, Fitzpatrick R, Roberts K: Including qualitative research in systematic reviews: opportunities and problems. J Eval Clin Pract 2001, 7:125-133.

123. Thompson SG, Sharp SJ: Explaining heterogeneity in meta-analysis: a comparison of methods. Stat Med 1999, 18:2693-2708.

124. Thompson SG: Controversies in meta-analysis: the case of the trials of serum cholesterol reduction. Stat Methods Med Res 1993, 2:173-192.

125. Riley RD, Higgins JP, Deeks JJ: Interpretation of random effects metaanalyses. BMJ 2011, 342:d549.

126. Cook DJ, Guyatt GH, Ryan G, Clifton J, Buckingham L, Willan A, Mcllroy W, Oxman AD: Should unpublished data be included in meta-analyses? Current convictions and controversies. JAMA 1993, 269:2749-2753.

127. Scherer RW, Huynh L, Ervin AM, Taylor J, Dickersin K: ClinicalTrials.gov registration can supplement information in abstracts for systematic reviews: a comparison study. BMC Med Res Methodol 2013, 13:79.

128. Juni $P$, Holenstein F, Sterne J, Bartlett C, Egger M: Direction and impact of language bias in meta-analyses of controlled trials: empirical study. Int J Epidemiol 2002, 31:115-123.

doi:10.1186/1475-2875-12-442

Cite this article as: Visser et al:: Serum lipids and lipoproteins in malaria - a systematic review and meta-analysis. Malaria Journal 2013 12:442.

\section{Submit your next manuscript to BioMed Central and take full advantage of:}

- Convenient online submission

- Thorough peer review

- No space constraints or color figure charges

- Immediate publication on acceptance

- Inclusion in PubMed, CAS, Scopus and Google Scholar

- Research which is freely available for redistribution 